\title{
Analysis of the vestigial tail mutation demonstrates that Wnt-3a gene dosage regulates mouse axial development
}

\author{
Tamara L. Greco, ${ }^{1}$ Shinji Takada, ${ }^{2,3,5}$ Matthew M. Newhouse, ${ }^{1,4,5}$ Jill A. McMahon, ${ }^{2}$ \\ Andrew P. McMahon, ${ }^{2}$ and Sally A. Camper ${ }^{1,6}$ \\ ${ }^{1}$ Department of Human Genetics, University of Michigan Medical School, Ann Arbor, Michigan 48109-0618 USA; ${ }^{2}$ \\ Department of Molecular and Cellular Biology, The Biolabs, Harvard University, Cambridge, Massachusetts 02138 USA
}

Mice homozygous for the recessive mutation vestigial tail (vt), which arose spontaneously on Chromosome 11, exhibit vertebral abnormalities, including loss of caudal vertebrae leading to shortening of the tail. Wnt-3a, a member of the wingless family of secreted glycoproteins, maps to the same chromosome. Embryos homozygous for a null mutation in Wnt-3a (Wnt-3a ${ }^{n e o}$ ) have a complete absence of tail bud development and are truncated rostral to the hindlimbs. Several lines of evidence reveal that $v t$ is a hypomorphic allele of Wnt-3a. We show that Wnt-3a and $v t$ cosegregate in a high-resolution backcross and fail to complement, suggesting that $W n t-3 a^{\text {neo }}$ and $v t$ are allelic. Embryos heterozygous for both alleles have a phenotype intermediate between that of $W n t-3 a^{n e o}$ and $v t$ homozygotes, lacking a tail, but developing thoracic and a variable number of lumbar vertebrae. Although no gross alteration in the Wnt-3a gene was detected in vt mice and the Wnt-3a coding region was normal, Wnt-3a expression was markedly reduced in $v t / v t ~ e m b r y o s$ consistent with a regulatory mutation in Wnt-3a. Furthermore, the analysis of allelic combinations indicates that Wnt-3a is required throughout the period of tail bud development for caudal somitogenesis. Interestingly, increasing levels of $W n t-3 a$ activity appear to be necessary for the formation of more posterior derivatives of the paraxial mesoderm.

[Key Words: Axial development; mouse; vestigial tail mutation; Wnt-3a gene; caudal somitogenesis; paraxial mesoderm]

Received October 24, 1995; revised version accepted December 5, 1995

The vertebrae of the axial skeleton arise from segmented paraxial mesodermal precursors, the somites that are paired epithelial clusters lying on either side of the midline mesoderm of the notochord. Initially, the somite is an undifferentiated ball of cells. Subsequently, it undergoes a progressive regionalization generating dermal (dermatome), muscle (myotome), and cartilage (sclerotome/ precursors in response to a complex network of signals. For example, the initiation of sclerotomal development, and consequently the formation of vertebrae, appears to be regulated by a notochord-derived signalSonic hedgehog (Fan and Tessier-Lavigne 1994; Johnson et al. 1994; Fan et al. 1995). Somite formation in the mouse is a protracted developmental process initiated at primitive streak stages in the early gastrulating embryo, 8.0 days post coitum (dpc), and continuing until $13.5 \mathrm{dpc}$ (Tam and Tan 1992). When complete, $\sim 65$ somite pairs

\footnotetext{
Present addresses: ${ }^{3}$ Center for Molecular and Development Biology, Kyoto University, Kitashirakawa, Sakyo-ku, Kyoto 606-01, Japan; ${ }^{4}$ Department of Molecular and Human Genetics, Baylor College of Medicine, Houston, Texas, 77030 USA.

${ }^{5}$ These authors contributed equally to this work.

${ }^{6}$ Corresponding author.
}

are formed. These pairs give rise to a rostral-caudal progression of vertebrae generating an adult skeleton comprising 4 occipital, 7 cervical, 13 thoracic, 6 lumbar, 4 sacral, and $\sim 30$ caudal vertebrae that make up the tail (Gruneberg 1963; Rugh 1990).

Fate mapping studies indicate that the first somites formed are derived from mesodermal precursors arising at the anterior limit of the primitive streak (Tam and Beddington 1987; Tam 1989). As development continues, the primitive streak is gradually lost and by $9.0 \mathrm{dpc}$, or when the embyro has $\sim 24-26$ somites, a transition takes place wherein a new structure, the tail bud, contributes the mesodermal precursors that generate all of the remaining somites (Schoenwolf 1977; Tam 1984, 1986; Tam and Tan 1992). Thus, the occipital, cervical, and thoracic vertebrae are probably derived from the primitive streak, whereas lumbar, sacral, and caudal vertebrae of the tail are derived from the tail bud.

Classic genetic studies have identified $>100$ mouse mutants with skeletal defects (Lyon and Searle 1989), and this number is increasing with the advent of gene targeting (Brandon et al. 1995), indicating that numerous genes are required for proper development of the axial skeleton. These mutants serve as powerful tools to ana- 
lyze the pathway of axial skeleton development by identifying genes that disrupt early steps, such as gastrulation, and later-acting genes that are required more specifically for vertebral formation.

Vestigial tail $(\mathrm{vt})$ is an autosomal recessive mutation that results in viable animals with reduced, kinked tails (Heston 1951; Gruneberg 1957, 1974). Typically, many caudal vertebrae are absent, and those that remain exhibit severe morphological abnormalities. Occasionally presacral vertebrae are missing, and caudal, lumbar, and sacral vertebrae exhibit two centers of ossification rather than a single one in the midline (Heston 1951; Gruneberg 1957). From the analysis of somite-stage embryos it was suggested that these vertebral defects are probably secondary to the reduced recruitment of cells to the caudal somites during somitogenesis (Gruneberg 1974). In addition there were apparent anomalies in the development of the caudal neural tube in the region where somite formation was defective (Gruneberg 1974).

We have examined the possibility that $v t$ may be related to Wnt-3a, which also maps to Chromosome 11 (Nusse et al. 1991). Wnt-3a is a member of a large family of secreted glycoproteins that regulate many distinct aspects of vertebrate and invertebrate development (McMahon et al. 1992; Nusse and Varmus 1992). Expression of Wnt-3a is first detected at late primitive streak stages, starting $\sim 7.5 \mathrm{dpc}$, and continues in the tail bud until at least $9.5 \mathrm{dpc}$. Gene-targeting studies in the mouse demonstrate that Wnt-3a is required for the development of somites and the tail bud. Mice homozygous for a null allele $\left(W n t-3 a^{n e o}\right)$ can develop until $12.5 \mathrm{dpc}_{\text {; }}$ however, they lack all somites caudal to somite 9 and fail to form a tail bud. Therefore, the body axis usually terminates between the fore- and hindlimbs (Takada et al. 1994). On the basis of this severe somitic phenotype and the absence of tail bud formation it was suggested that Wnt-3a signaling may regulate somite fate and establishment or maintenance of the tail bud (Takada et al. 1994). Here we provide several lines of evidence that the defect in $v t$ animals results from the generation of a hypomorphic allele of Wnt-3a. In addition, by generating embryos carrying different allelic combinations, thereby progressively lowering the levels of Wnt-3a expression, somitogenesis and subsequent axial skeleton development can be arrested at increasingly more anterior positions. These data suggest that Wnt-3a is required throughout tail bud development for the elaboration of new somites. Moreover, alteration of the gene dosage suggests that increasing levels of Wnt-3a activity are necessary for the development of more posterior somites.

\section{Results}

\section{Wnt-3a and vt cosegregate on mouse Chromosome 11}

The $v t$ mutation arose spontaneously in a C57BR stock in 1947 (Heston 1951). The mutation was subsequently crossed to a variety of genetic backgrounds in the course of classic genetic mapping experiments and has been maintained recently with the recessive wavy coat marker (wa2) mutation by backcrossing to a hybrid stock composed of C57BL6/J and C3H/HeJ. Thus, the mutated allele in $v t$ mice is derived from the C57BR strain.

Classic genetic mapping localized $v t$ relative to several other phenotypic markers on the central portion of Chromosome 11 (Michie 1955b; Searle 1961). To place $v t$ relative to molecular markers and to evaluate candidate genes we generated a backcross with a vestigial tailed stock carrying wa2 and the wild mouse Mus castaneus. A range of tail phenotypes were represented among the progeny. Of the 447 progeny collected, 207 were typed as $v t / v t$ and 240 as $v t /+$ on the basis of tail length and degree of kinking. The average tail length of $v t /+$ mice at 3-6 weeks of age was $7.3 \pm 0.8 \mathrm{~cm}(n=131)$ compared with $1.4 \pm 1.3 \mathrm{~cm}(n=109)$ for $v t / v t$ mice. The ratio of normal to vestigial-tailed mice did not differ significantly from the expected values for this cross $\left(\chi^{2}=2.42\right.$, $\mathrm{df}=1, P>0.1$ ). Sixty-seven progeny were scored phenotypically for $v t$ and $w a 2$ and typed for markers spanning the proximal half of Chromosome 11, including D11Mit1, D11Mit22, D11Mit5, and granulocyte macrophage colony-stimulating factor (Csfgm). In all cases, the $M$. castaneus alleles were distinguishable from the alleles carried in the vestigial-tailed stock. The location of $v t$ and $w a 2$ relative to these molecular markers was determined by minimization of recombination and haplotype analysis of these and the additional animals. The following gene order and genetic distances were obtained: centromere-D11Mit1-15 cM-wa2-19 cM-D11Mit22-3.6 $\mathrm{cM}-C s f g m-3.5 \mathrm{cM}-\mathrm{vt}-2.2 \mathrm{cM}-D 11$ Mit5 (Fig. 1). Analysis of this backcross provides a basis for correlation of the molecular and classic genetic maps and places $v t \sim 5 \mathrm{cM}$ distal to the location predicted in the consensus map (Lossie et al. 1994).

We considered both osteonectin (Sparc) and Wnt-3a as candidate genes. Sparc encodes a secreted protein that is proposed to have a role in bone morphogenesis and somite formation (Mason et al. 1986; Sage and Bornstein 1991; Lane and Sage 1994). Although its precise function is not known, antibody neutralization of osteonectin in Xenopus embryos has been shown to disrupt caudal development in an analogous fashion to the backbone truncation and caudal defects observed in $v t / v t$ embryos (Purcell et al. 1993). Sparc had been mapped previously to the central portion of Chromosome 11 with a $99 \%$ probability of being within $3.9 \mathrm{cM}$ of Csfgm (Buckwalter et al. 1991). To evaluate $S p a r c$ as a candidate gene for $v t$, 173 backcross progeny were typed for Sparc using a restriction fragment-length protein (RFLP) revealed by Southern blot hybridization. Four recombinants were detected, placing Sparc $2.3 \pm 1.1 \mathrm{cM}$ proximal to $v t$ and unambiguously eliminating it as a candidate gene (Fig. 1).

Wnt-3a encodes a putative signaling molecule essential for caudal development of the tailbud and paraxial mesoderm (Takada et al. 1994) and had been assigned to Chromosome 11 but not localized (Nusse et al. 1991). To localize Wnt-3a, the $M$. castaneus backcross segregating $v t$ was typed using an RFLP that distinguished the $M$. castaneus allele from Mus musculus and Mus domesticus alleles of Wnt-3a. No recombinants were observed in 


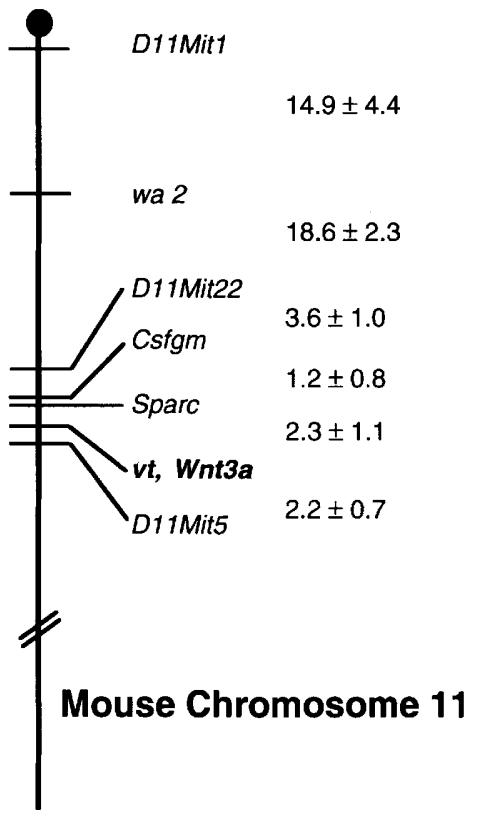

Figure 1. Cosegregation of $v t$ and Wnt-3a in a high-resolution backcross. A map of proximal mouse Chromosome 11 was constructed based on haplotype analysis of markers in a backcross segregating $w a 2$ and $v t$. The genetic distances between loci are given in centimorgans with estimated standard deviations (Lyon and Searle 1989). No recombinants were detected between Wnt-3a and $v t$ in $\mathbf{4 4 5}$ of backcross progeny analyzed.

363 progeny. An additional 82 animals were typed using an interval mapping strategy. Animals exhibiting recombination between D11Mit22 and D11Mit5 were analyzed further by PCR amplification of a simple sequence length polymorphism (SSLP) in the $3^{\prime}$-untranslated region (UTR) of Wnt-3a (see Materials and methods). No recombinants were detected. The lack of crossovers between $v t$ and Wnt-3a in a total of 445 offspring demonstrates that $v t$ and $W n t-3 a$ are within $0 \pm 0.7 \mathrm{cM}$ of each other $(95 \%$ confidence level). To date, no genes other than Wnt-3a have been mapped to the nonrecombinant region around the $v t$ locus. The colocalization of $v t$ and Wnt-3a provides compelling genetic evidence that a lesion in Wnt-3a may be responsible for the $v t$ mutation.

\section{Wnt-3a coding sequences are intact in vt/vt mice}

The gross integrity of $W n t-3 a$ was examined by Southern blot analysis using a Wnt-3a cDNA probe that contained almost all of the coding region and a portion of the $3^{\prime}$ UTR (Roelink and Nusse 1991). Digestion of genomic DNA samples from several different inbred strains of mice with 26 different restriction enzymes revealed RFLPs between C57BL6/J and C57/BR with StuI and SacI (data not shown). Further RFLP analysis with $S t u I$ and SacI confirmed that $v t / v t$ mice contain the C57BR allele of Wnt-3a. No differences between $v t / v t$ mice and C57BR mice were detected with any of the 26 restriction enzymes tested (data not shown). Therefore, the lesion in
Wnt-3a does not appear to be a gross rearrangement or a large duplication or deletion.

We examined RNA prepared from mutant and normal adult mice and 12.5-dpc embryos by Northern blot using the Wnt-3a cDNA probe. Wnt-3a mRNA has been detected previously in embryos from 7.5 (Takada et al. 1994) to 12.5 dpc by in situ hybridization (Roelink and Nusse 1991) and in adult lungs by Northern blot analysis (Roelink and Nusse 1991). The sensitivity of our Northern blots was not sufficient to detect Wnt-3a mRNA in 12.5-dpc embryos, but the Wnt-3a transcripts in adult lung were readily detectable and appeared to be the same size in normal and $v t$ mice (data not shown).

The Wnt-3a cDNA-coding region was cloned and sequenced from $v t$ mice. Two overlapping fragments encompassing $90 \mathrm{bp}$ of $5^{\prime}$ UTR, the $1055 \mathrm{bp}$ of coding sequences, and $25 \mathrm{bp}$ of the $3^{\prime}$ UTR were sequenced. The Wnt-3a cDNA fragments were cloned from three separate RT-PCR amplifications of different preparations of adult lung mRNA. For each fragment, the nucleotide sequence of at least three independent clones was determined. Nucleotide changes not confirmed by independent trials were attributed to $T a q$ polymerase errors. Three silent changes were detected between $v t / v t$ and the published BALB/c sequence (Roelink and Nusse 1991). At nucleotide 839, a $\mathrm{T} \rightarrow \mathrm{C}$ transition was observed, and $A \rightarrow G$ transitions were noted at nucleotides 932 and 974 . These silent changes probably represent polymorphisms specific to the C57BR strain.

In summary, examination of the Wnt-3a gene by Southern analysis and the mRNA by Northern and cDNA sequence analysis revealed no signs of the most obvious mutations: gene duplication, deletion, improper splicing, and coding errors. Clearly, $v t$ mice have the potential to produce functional Wnt-3a. Thus, $v t$ may represent a regulatory mutation affecting levels of Wnt$3 a$ expression.

\section{Reduced expression of Wnt-3a in vt/vt embryos}

Wnt-3a expression was examined in $+/+,+/ v t$, and $v t / v t$ embryos at $9.5,10.5$, and $11.5 \mathrm{dpc}$. Previous studies have demonstrated that Wnt-3a is expressed in the tail bud at $9.5 \mathrm{dpc}$ (Takada et al. 1994) but it was not clear whether this expression persists throughout the later period of caudal somite formation. Whole-mount in situ hybridization was performed with a minimum of five embryos of each genotype at each stage. In addition, we examined $+1+$ embryos that were derived from two different matings, C57BR (the strain on which the $v t$ mutation arose) and $\mathrm{C} 57 \mathrm{BL} 6 / \mathrm{J} \times \mathrm{C} 3 \mathrm{H} / \mathrm{HeJ}$ (the $\mathrm{F}_{1}$ background on which the $v t$ mutation is maintained).

At all stages Wnt-3a expression was observed in the tail bud of $+/+$ and $+/ v t$ embryos consistent with Wnt$3 a$ having a role in late somitogenesis (Fig. 2). In contrast, Wnt-3a expression was barely detectable in the tail bud of $v t / v t$ embryos even at $9.5 \mathrm{dpc}$. Expression in the dorsal central nervous system (CNS) of $v t / v t$ embryos appeared similar to that of $+/+$ and $+/ v t$ embryos suggesting a preferential loss of Wnt-3a expression in the tail bud. 
Figure 2. Whole-mount in situ hybridization demonstrates that Wnt-3a mRNA is reduced in the tail bud of $v t / v t$ embryos. Whole-mount in situ hybridization of a Wnt-3a probe (Takada et al. 1994) to 9.5, 10.5 , and $11.5 \mathrm{dpc}$ mouse embryos of the following genotypes: $+/+,+/ v t, v t / v t$. A minimum of five embryos of each genotype were analyzed in a single experiment. Only the tail region is shown for 10.5 and $11.5 \mathrm{dpc}$ embryos. Expression of Wnt-3a in the forebrain is indistinguishable at $9.5 \mathrm{dpc}$ among the genotypes (arrows). In contrast, tailbud expression larrowheads) is greatly reduced in $v t / v t$ embryos relative to the levels observed in $+/ v t$ and $+1+\mathrm{em}$ bryos.

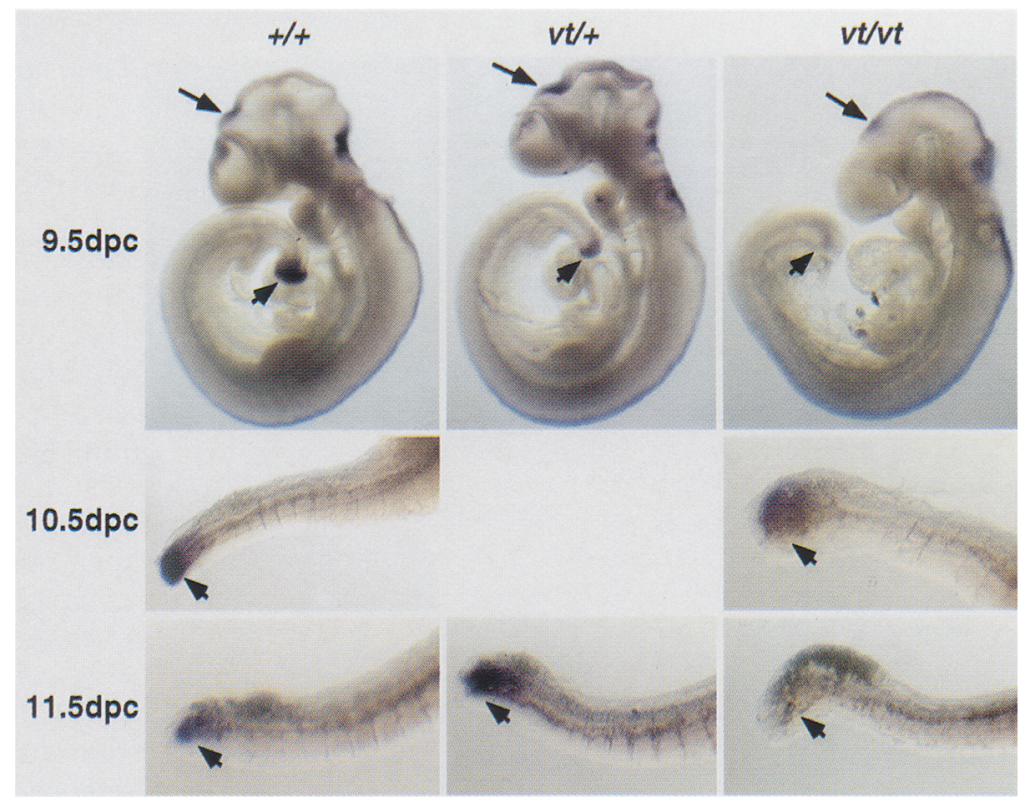

Interestingly, the reduction in Wnt-3a expression precedes the appearance of an overt loss of somites in $v t / v t$ embryos that is first apparent $\sim 10.5-11.0 \mathrm{dpc}$.

To eliminate the possibility that the uterine environment of $v t / v t$ mothers could contribute to differences in fetal expression (Heston 1951), we took advantage of our ability to genotype embryos prior to the appearance of an obvious tail phenotype. Female heterozygotes $(v t /+1$ that inherited a normal allele from a C57BL/6J mother were mated with $v t / v t$ males. The $v t / v t$ and $v t /+\mathrm{fe}-$ tuses were distinguished by monitoring for the inheritance of the C57BL6/J allele of Wnt-3a using an SSLP (Materials and methods). As expected, the intensity of staining for Wnt-3a was reduced considerably in $v t / v t$ $(n=5)$ relative to $+/ v t$ embryos $(n=3)$ (data not shown). In summary, the $v t$ mutation leads to a reduction in $W n t-3 a$ expression that precedes the $v t$ phenotype. Together, the genetic cosegregation analysis and gene expression studies support the hypothesis that $v t$ is a hypomorphic allele of Wnt-3a.

\section{Wnt-3a and vt are noncomplementary}

To confirm this hypothesis, an allelism test was performed between $v t$ and Wnt- $3 a^{\text {neo }}$, a likely null allele generated by gene targeting (Takada et al. 1994). Wnt$3 a^{\text {neo }}$ homozygotes exhibit embryonic lethality by 12.5 $\mathrm{dpc}$, but heterozygotes are viable (Takada et al. 1994). Genetic analysis has shown that the $v t$ lesion is viable with no evidence of lethality (Heston 1951). Females heterozygous for the null allele $\left(W n t-3 a^{n e o} /+\right)$ were mated with $v t / v t$ males and progeny were examined at birth. A 50:50 distribution of normal and affected mice would be expected for noncomplementing alleles. However, lack of aberrant tail morphology among the progeny could either be evidence of complementation between Wnt-
$3 a$ and $v t$ or lethality of the compound heterozygotes $\left(W n t-3 a^{n e o} / v t\right)$. Thus, the allelism test was performed with Wnt-3aneo/ + mice containing the polymorphic C57BL6/J Wnt $-3 a^{+}$allele, permitting unambiguous genotyping of the progeny.

At birth, 60 progeny had normal tails and 51 had no tails (Figs. 3 and $4 \mathrm{~B}$ ). By $\chi^{2}$ analysis this distribution does not differ significantly from the 50:50 distribution predicted for noncomplementarity of $v t$ and Wnt-3a $(P>0.25)$. To confirm that all affected progeny were compound heterozygotes, neonates were genotyped at the Wnt-3a locus for the SSLP that distinguishes the Wnt$3 a^{+}$allele (C57BL/6) from the embryonic stem-cell-derived Wnt-3aneo $(129 / \mathrm{Sv})$ and $v t(\mathrm{C} 57 \mathrm{BR}$ ) alleles (Fig. 3). There was a perfect correlation between the phenotype and the genotype determined by the Wnt-3a SSLP. The wild-type C57BL/6 allele of Wnt-3a was present in all of the neonates with tails but was not present in any of the affected progeny, demonstrating that Wnt-3a and $v t$ are noncomplementing alleles.

\section{Abnormalities in compound heterozygotes are more extreme than in vt homozygotes}

Multiple features of the compound heterozygote phenotype were intermediate in severity between those exhibited by $v t / v t$ or $W n t-3 a^{n e o} / W n t-3 a^{n e o}$ mice. The vestigial tail evident in almost all $v t / v t$ neonates (Fig. 4A) was completely lacking in compound heterozygotes (Fig. 4B, center). The most severely affected compound heterozygotes had smaller bodies, hindlimb paralysis, and spina bifida of the posterior neural tube (Fig. 4B, right). Five litters from the allelism test cross were sequestered to assess postnatal lethality. Approximately $50 \%$ of the compound heterozygotes lived longer than 4 weeks (12 of 27 ), compared with $90 \%$ of $v t /$ + littermates (19 of 21 ), 


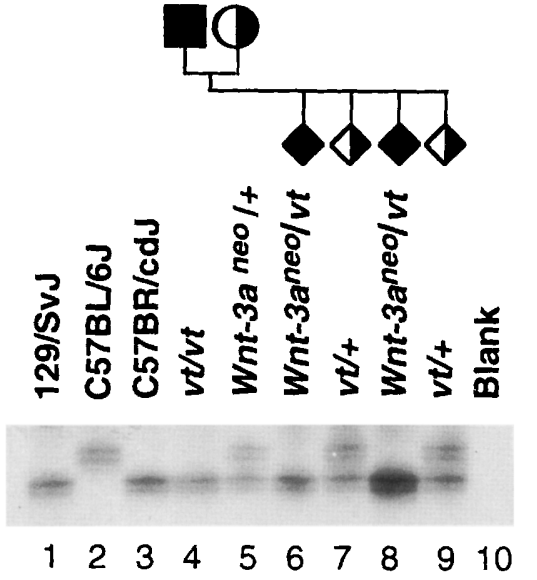

Cross: Wnt-3aneo/+ X vt/vt Progeny:

\begin{tabular}{lcc} 
& \multicolumn{2}{c}{ Phenotype } \\
Genotype & Tail & No tail \\
\hline$v t / t$ & 51 & 0 \\
Wnt-3aneo/vt & 0 & 29 \\
Not determined & 9 & 22 \\
\hline Total & 60 & 51
\end{tabular}

Figure 3. Noncomplementation of Wnt-3a and $v t$. Male $v t / v t$ mice were mated with $W n t-3 a^{\text {neo }} /+$ females, and the phenotype (tail or no tail) of the progeny was assigned at birth. The genotype at the Wnt-3a locus was determined by PCR amplification of a polymorphic simple sequence repeat in the $3^{\prime}$ UTR of Wnt-3a. A similar pattern of fragments was produced using genomic DNA prepared from $129 / \mathrm{SvJ}$ and C57BR/cd) mouse strains (lanes 1,3), and a larger product was obtained from C57BL6/J genomic DNA (lane 2). The $v t / v t$ parent (lane 4) is homozygous for the smaller fragment, which is identical in size to the product amplified from C57BR/cdJ genomic DNA, the strain on which $v t / v t$ arose. The $W n t-3 a^{\text {neo }}$ allele was generated in embryonic stem cells derived from the $129 / \mathrm{SvJ}$ mouse strain. Chimeric mice were mated to C57BL6/J mice to produce Wnt$3 a^{n e o} /+$ heterozygotes and maintained by crossing with C57BL6/J (Takada et al. 1994). Wnt-3aneo + females (lane 5) are heterozygous for the embryonic stem cell-derived Wnt $3 a^{\text {neo }}$ allele (lower band) and the larger C57BL6/J derived $W n t 3 a^{+}$allele. Analysis of four progeny of the allelism test is illustrated (lanes 6-9). PCR amplification of genomic DNA revealed the presence of the C57BL6/J Wnt $3 a^{+}$allele in progeny with tails (half-filled diamonds, lanes 7,9 ) but not in the tailless progeny (solid diamonds, lanes 6,8 ). The results are summarized at the bottom. Fifty-one newborns with tails were genotyped as $v t /+$, and 29 newborns without tails were genotyped as $W n t-3 a^{n e o} / v t$ compound heterozygotes. No genotyping information was available for the 31 progeny classified as "not determined" because they died before tissues were collected for DNA preparation or the DNA was insufficient for analysis.

demonstrating a significant reduction in the viability of compound heterozygotes $(P<0.001)$. For most compound heterozygotes the cause of death was not clear, but in several cases an accumulation of urine was observed in kidneys and ureters, and intestines were hyperextended, suggesting a defect in excretory system function. Defects in the second through fourth sacral vertebrae are commonly associated with neurogenic bladder in humans (Stark 1977).

Skeletal defects in compound heterozygotes extended more anteriorly than those of $v t / v t$ mice (Figs. 4 and 5). Ten skeletons from $v t /+$ neonates were analyzed, and all showed normal structure and number of vertebrae through the cervical, thoracic, lumbar, sacral, and caudal regions. Fourteen skeletons of $v t / v t$ neonates revealed normal development through the sacral region, but the number of caudal vertebrae with normal morphology was only 2-15 compared with 18-25 observed in $v t /+$ mice (Fig. 5). In addition, the most caudal vertebrae in $v t / v t$ neonates exhibit abnormal centers of ossification. These observations are consistent with published reports of the $v t / v t$ phenotype (Heston 1951; Gruneberg 1957), except that no sacral defects were observed in this sampling of our stock (Fig. 5). The skeletal phenotype of 12 compound heterozygotes was also variable (Fig. 5), but in all cases the defects were much more severe than those observed in $v t / v t$ mice. None of the Wnt-3aneo/vt mice had a full complement of lumbar vertebrae, and no normal sacral vertebrae were observed in individuals of this group. The most severely affected compound heterozygotes exhibited a reduced number of thoracic vertebrae and deformities as far anterior as the seventh thoracic vertebra (Fig. 4F). The results of this phenotypic analysis are summarized (Fig. 5). Whereas the skeletal phenotypes observed for each genotype were variable, no overlap was observed between genotypes.

To confirm that the skeletal phenotype of neonates is an accurate indicator of early developmental events, we examined the formation of somites at 10.5 and $11.5 \mathrm{dpc}$ with the marker Mox-1. Mox-1 is first expressed in the presomitic mesoderm, continues into newly formed epithelial somites $(8.0-9.5 \mathrm{dpc})$, and persists as the epithelial somites differentiate to the sclerotome, dermatome, and myotome (9.5-11.5 dpc) (Candia et al. 1992). In the Wnt $-3 a^{\text {neo }} /$ Wnt $-3 a^{\text {neo }}$ mutants, as reported previously (Takada et al. 1994), somites with normal Mox-1 expression only extend to the level of the forelimb bud (Fig. $6 \mathrm{D})$. Somite development in compound heterozygotes (Wnt-3aneo/vt) extended just posterior of the hindlimb bud (hindlimb ends at somite 28, lumbar region). Some nonepithelial Mox-1 expression was observed for a short distance caudal to this position, and then expression terminated more rostral to the tip of the tail than in $+/+$ embryos (Fig. 6, cf. A and C). Skeletal analysis of Wnt$3 a^{\text {neo }} / v t$ neonates revealed morphological abnormalities rostral to the last somites observed to express Mox-1 in embryos (Fig. 5), indicating that the expression of Mox-1 is not sufficient for normal somite function. At $10.5 \mathrm{dpc}$ the $v t / v t$ embryos showed similar patterns of Mox-1 expression to $+1+$ embryos, indicating that somite formation extending to the precursors of the anterior tail vertebrae (initiated at somite 35) was normal in $v t / v t$ embryos (Fig. 6B). However, by $11.5 \mathrm{dpc}$, clear differences were apparent in somite number and Mox-1 expression in the caudal region of $v t / v t$ embryos (Fig. $6 \mathrm{~F}$ ) relative to 

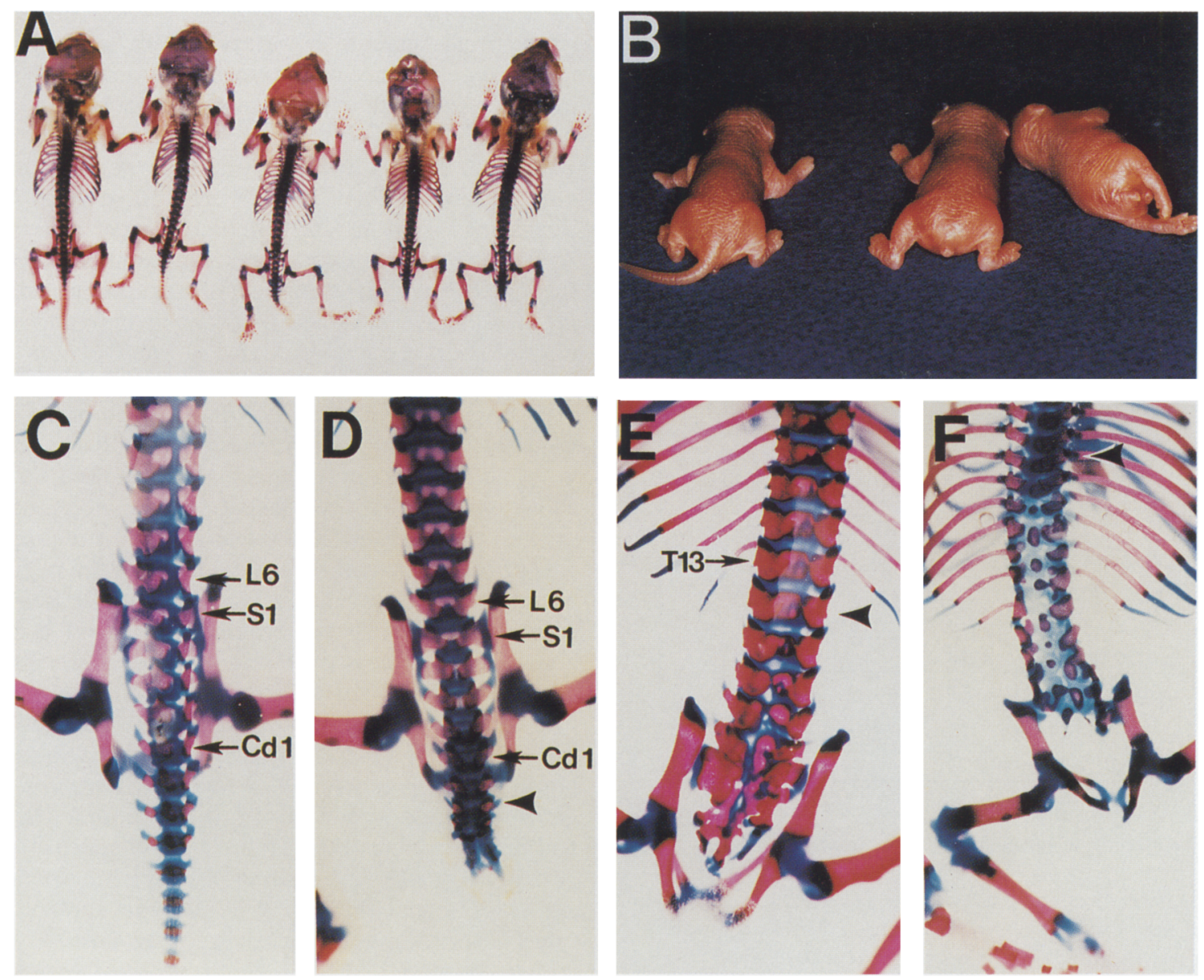

Figure 4. (A) Skeletal abnormalities of $v t / v t$ mice are less severe than those observed in $W n t 3 a^{n e o} / v t$ compound heterozygotes. The skeletal morphology was analyzed by staining bone with alizarin red and cartilage with alcian blue. In $A$, analysis of a normal day 2 neonate $(v t /+$, far left $)$ and four $v t / v t$ littermates reveals the range of deformed tails characteristic of $v t / v t$ mice. Progeny of the allelism test $(B)$ included a normal neonate (far left) and two compound heterozygotes $\left(W n t-3 a^{\text {neo }} / v t\right.$ ) with no visible tail. Most compound heterozygotes had normal hindlimb reflexes (middle), but the most severely affected $W n t-3 a^{\text {neo }} / v t$ mice had hindlimb paralysis and spina bifida (far right). The skeletons of $v t /+$ neonates $(C)$ were compared with $v t / v t(D)$ and $W n t-3 a^{\text {neo }} / v t$ skeletons $(E, F)$. The position of the most posterior normal vertebra is indicated with a solid arrowhead. The last thoracic (T13), the last lumbar (L6), the first sacral (S1), and the first caudal (Cd 1) vertebra are indicated as landmarks (arrows in $C-E$ ). Vertebral defects, including abnormal centers of ossification, malformations, and fusions, were evident in the caudal region of all $v t / v t$ mice $(D$; Cd $3=$ normal, arrowhead), in the lumbar region of a $W n t-3 a^{n e o} / v t$ mouse with an intermediate phenotype $(E ; \mathrm{L} 1=$ normal, arrowhead $\}$, and the thoracic region of the most severely affected $W n t-3 a^{\text {neo }} / v t$ mice $(F ; \mathrm{T} 6=$ normal, arrowhead $)$.

wild-type littermates (Fig. 6E). Thus, there is a good correlation between the axial position at which somite formation is disrupted and the later arising skeletal phenotypes in the different allelic combinations, indicating that the loss or disruption of vertebrae is a primary consequence of the failure to form normal somites.

\section{Discussion}

The data presented here are consistent with the hypothesis that $v t$ is a hypomorphic allele of Wnt-3a. First, no recombination occurred between Wnt-3a and $v t$ in 445 offspring from the mapping crosses, placing $W n t-3 a$ and $v t$ within $0.7 \mathrm{cM}$ on Chromosome 11 . In addition, a null mutation in Wnt-3a failed to complement $v t$. Compound heterozygotes have a strikingly severe failure of paraxial mesoderm formation and lethal phenotype. In $v t / v t$ mice the tail is shortened because of the absence of caudal vertebrae and kinked because of vertebral abnormalities, reflecting an underlying failure of caudal somite formation. The phenotype of $v t / v t$ embryos is therefore consistent with two facets of Wnt-3a expression: the observation that $W n t-3 a$ regulates somite formation at earlier stages $(7.5 \mathrm{dpc})$, and the persistent expression of Wnt$3 a$ in the tail bud to at least $12.5 \mathrm{dpc}$ (S. Takada and A. McMahon, unpubl). This indicates that Wnt-3a might also regulate the formation of tail bud-derived somites. Furthermore, Wnt-3a expression in the tail bud of $v t / v t$ embryos is reduced prior to the appearance of an overt phenotype in $v t / v t$ embryos. Finally, Wnt-3a encodes a secreted protein and would be expected to act non-cell autonomously. Genetic studies of the Drosophila rela- 


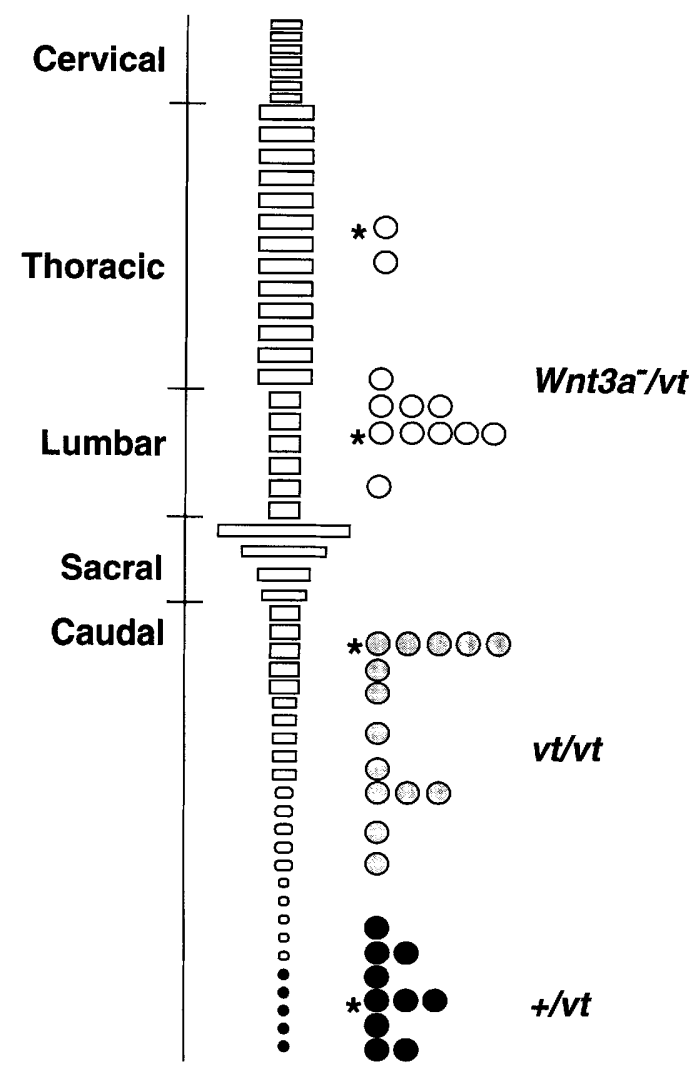

Figure 5. The skeletal abnormalities of vestigial-tailed homozygotes occur in more posterior positions than in Wnt $3 a^{\text {neo }}$ / $v t$ mice. The most posterior position at which normal vertebrae were apparent in an individual neonatal skeleton preparation is designated for mice genotyped as $W n t 3 a^{n e o} / v t$ (open circles), $v t / v t$ (shaded circles) and $v t /+$ (solid circles). Asterisks denote the skeletons illustrated in Fig. 4.

tive wingless [wg (Morata and Lawrence 1977)] and of mouse Wnt-1 (G. Vassileva, K. Stark, J.A. McMahon, and A.P. McMahon, in prep.) both demonstrate non-cell autonomy. Interestingly, analysis of aggregation chimaeras has also demonstrated that $v t$ is non-cell autonomous, consistent with a lesion in a secreted protein /Gruneberg and McLaren 1972).

It seems most likely that the reduced levels of Wnt-3a expression in $v t / v t$ embryos reflect an underlying quantitative defect in Wnt-3a transcription, although no genomic rearrangements that might cause this were apparent. Moreover, as expression in the dorsal spinal cord and brain appears normal at $9.5 \mathrm{dpc}$, loss of Wnt-3a expression may result from the disruption of a tail bud-specific regulatory region. However, although there is no evidence for differential splicing in either embryos or in adult lung, we cannot rule out a mutation that would affect efficiency of splicing or polyadenylation, or a mutation in the 3' UTR that would affect RNA stability and consequently reduce steady-state levels. Coincidentally, molecular lesions associated with three hypomorphic alleles of $w g$ have been detected recently, $3^{\prime}$ of the gene (van den Heuvel et al. 1993; Couso and Arias 1994) in a putative regulatory region.

If the $v t$ lesion is a point mutation in an enhancer region, it may be difficult to locate. Potential regulatory mutations can be quite distant from the promoter. For example, two regulatory mutations of Steel $(S 1), S P^{p a n}$ and $S I^{\text {con }}$, involve DNA rearrangements located $>100 \mathrm{~kb}$ upstream of the coding sequences (Bedell et al. 1995). Nothing is known about the transcriptional regulation of
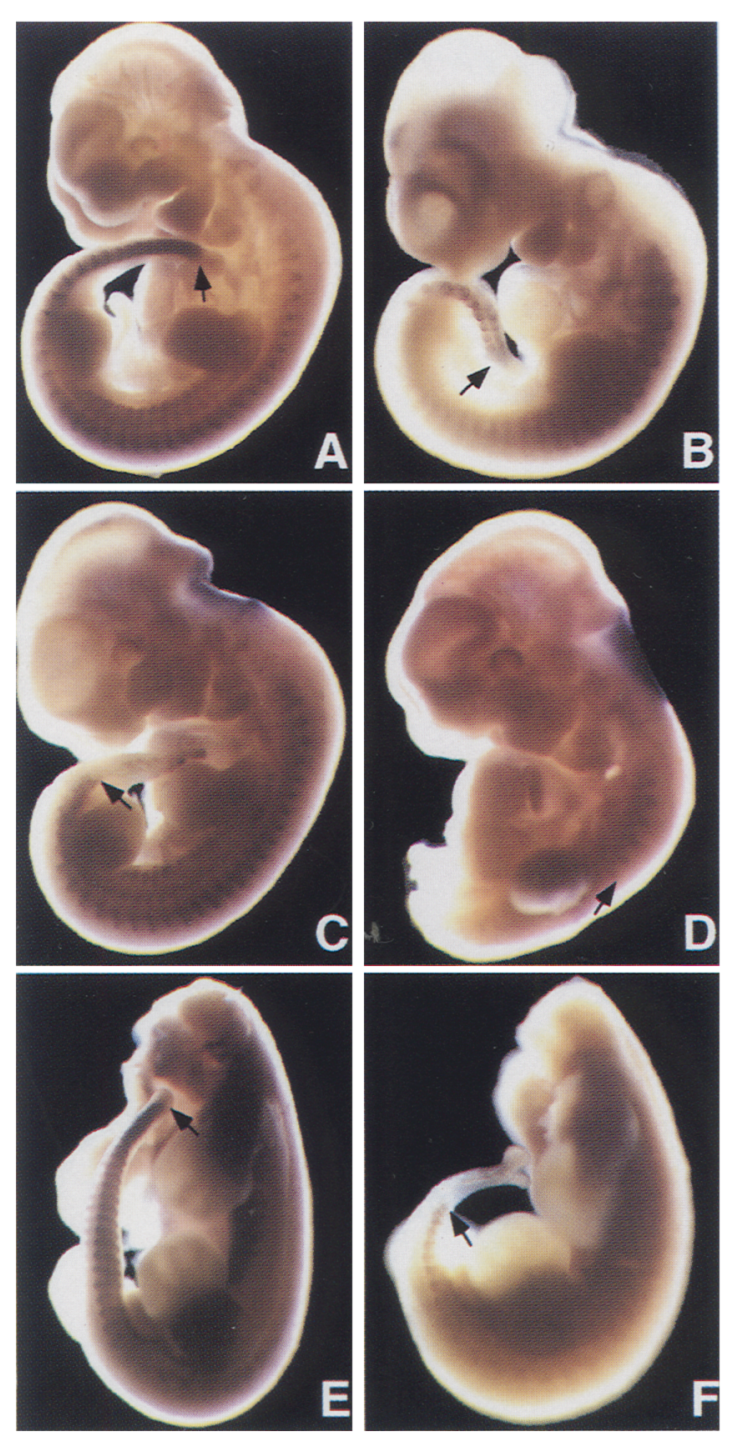

Figure 6. The axial level at which somite formation terminates correlates with the levels of Wnt-3a activity in different allelic combinations. Somite formation in $10.5 \mathrm{dpc}(A-D)$ and $11.5 \mathrm{dpc}(E-F)$ embryos was analyzed by examining expression of the somite marker, Mox-1. Embryos shown are as follows: $+/+\mid A, E), v t / v t(B, F), W n t-3 a^{\text {neo }} / v t(C)$, and Wnt-3aneo $/ W n t-$ $3 a^{\text {neo }}(D)$. Somite formation is visibly disrupted in $W n t-3 a^{\text {neo }} / v t$ $|C\rangle$ and Wnt $-3 a^{\text {neo }} / W n t-3 a^{\text {neo }}|D|$ embryos at $10.5 \mathrm{dpc}$ but is normal in $v t / v t$ embryos at this time. However, caudal somite formation fails to occur in $v t / v t$ embryos by $11.5 \mathrm{dpc}(F)$. Arrows mark the position at which Mox-1 expression teminates. 
Greco et al.

Wnt-3a, and the genomic structure has not been reported. Therefore, a precise molecular description of the $v t$ mutation is beyond the scope of the present study, but it is likely to provide an important insight into the regulation of signaling in the vertebrate tail bud. Until the molecular basis for the lesion is identified, we cannot exclude the possibility that $v t$ results from a lesion in another as yet unidentified gene within $0.7 \mathrm{cM}$ of Wnt$3 a$ that acts in the Wnt-3a pathway. An example of such nonallelic noncomplementaion has been observed between the Brachyury, or $T$ locus, and a neighboring gene (Rennebeck et al. 1995)

Although there are only two mutant alleles of Wnt-3a, $W n t-3 a^{\text {neo }}$ and $v t$, the functional consequences of five different Wnt-3a levels can be observed by comparing the phenotype of Wnt-3aneo homozygotes, Wnt-3aneo/vt compound heterozygotes, $v t$ homozygotes, and the Wnt$3 a^{\text {neo }} /+$ and $v t /+$ heterozygotes (Fig. 7). Analysis of this Wnt-3a allelic series demonstrates a requirement for increasing Wnt-3a dosage for the elaboration of progressively more caudal paraxial mesoderm derivatives. Homozygotes for the null allele exhibit no somite development posterior to somite 9 . Because most of these embryos die by $12.5 \mathrm{dpc}$, prior to vertebral formation, data on the skeleton are limited. However, somite 9 gives rise to the fifth and sixth cervical vertebrae; therefore, it is likely that the vertebral formation would usually terminate in the neck (Fig. 7). In Wnt $3 a^{\text {neo }} / v t$ compound heterozygotes, the small amount of Wnt-3a produced from one $v t$ allele is sufficient for prenatal viability and normal development of most thoracic vertebrae (Fig. 7). Higher levels of Wnt-3a produced in $v t / v t$ individuals completely rescue the postnatal viability and are sufficient for normal development of the lumbar and sacral regions, though not for the posterior tail vertebrae (Fig. 7). Finally, there is evidence that the reduced dosage of Wnt-3a in $v t /+$ mice is not always sufficient for the formation of all vertebrae, sometimes resulting in fewer caudal vertebrae and morphological irregularities that produce tail kinks (Gruneberg and McLaren 1972).

Genetic background contributes to the variation in severity of phenotype that we have observed within each genotype class; however, differences between groups are attributable to gene dosage. When $v t$ was placed on the $129 / \mathrm{Sv}$ J background, the most severe individual showed no caudal vertebrae development, but the sacral verte-

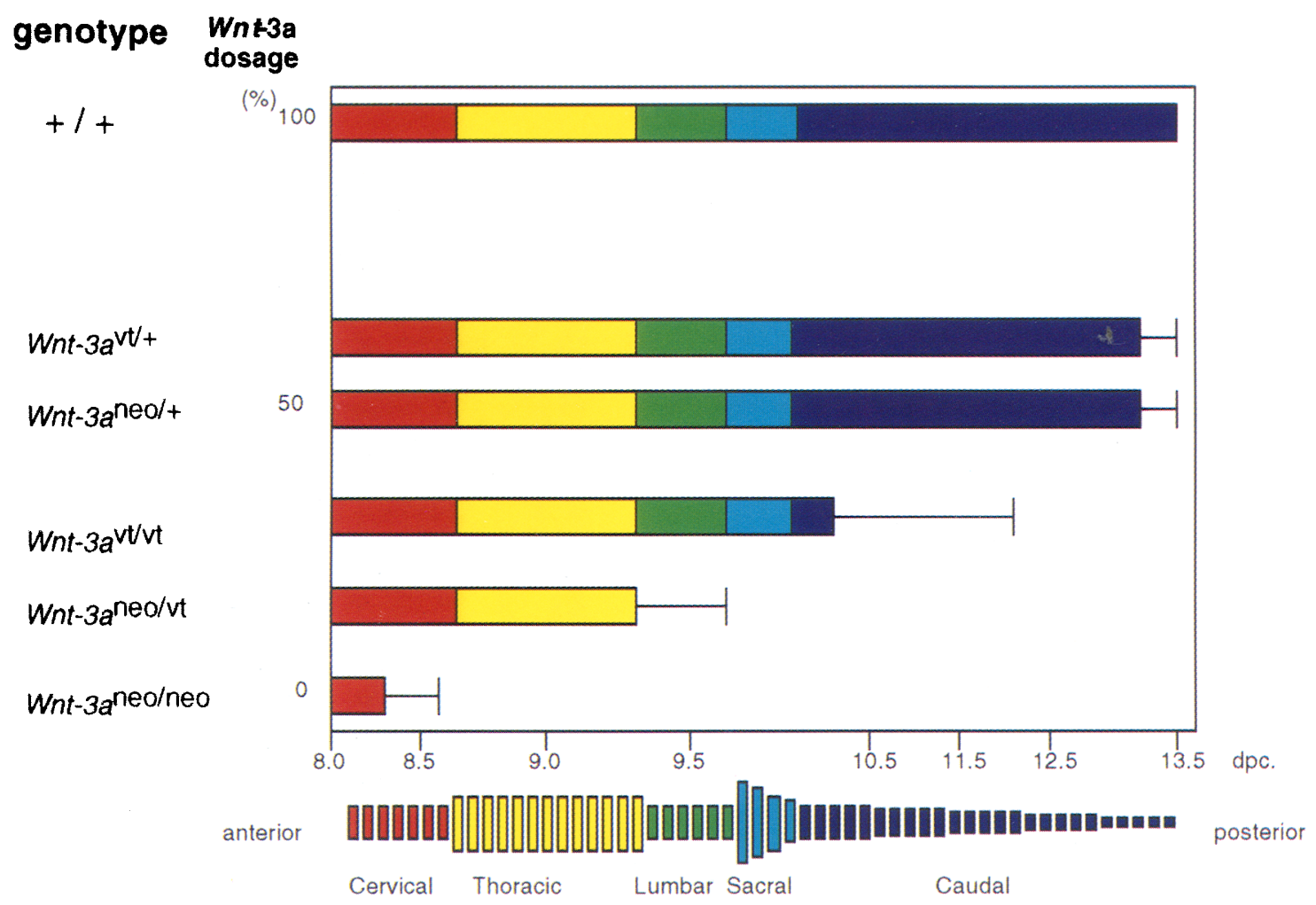

Figure 7. Relationship between Wnt-3a dosage and formation of axial skeleton. Lower doses of Wnt-3a cause more anterior defects in the skeleton. The vertebrae of the axial skeleton are depicted diagrammatically ( $x$-axis) with the approximate day of embryonic development at which each region develops. The genotype and estimated levels of Wnt-3a activity for the allelic series are indicated (y-axis). Bars depict the relative development of the skeleton based on observation of the Wnt- $3 a^{\text {neo }} /$ Wnt $-3 a^{\text {neo }}$ embryos (Takada et al. 1994), skeletal preparations of $v t / v t$ and $W n t-3 a^{\text {neo }} / v t$ neonates, and the observed tail morphology of adult $W n t-3 a^{n e o} /+$ mice and $v t /+$ backcross progeny. The bars suggest the phenotypic range of vertebral development for each genotype. The actual levels of $W n t-3 a$ expression from the $v t$ allele are not known. Thus, the position of mice carrying $v t$ alleles on the Wnt-3a activity scale is arbitrarily assigned at a position lower than that of the wild-type Wnt-3a allele but greater than that of the Wnt-3a null allele. 
brae were intact. Therefore the severity in the compound heterozygotes compared with $v t$ homozygotes is attributable to gene dosage and cannot be attributed to background effects. On an (C57BL6/J $\times 129 /$ SvJ) $F_{1}$ hybrid background, Wnt- $3 a^{\text {neo }}$ heterozygotes exhibit a low frequency $(10 \%$ of heterozygotes) of terminal tail kinks. On a $129 / \mathrm{SvJ}$ inbred background the penetrance is much higher and $80 \%$ of heterozygotes exhibit this phenotype (S. Takada, M. Hammerschmidt, and A.P. McMahon, unpubl.). Similarly, occasional tail kinks have been observed in $v t /+$ mice (Michie 1955a; Gruneberg and McLaren 1972), and we observed tail kinks in 1\%-2\% of the $v t /+$ progeny of the $M$. castaneus backcross. Thus, on the appropriate genetic backgrounds Wnt-3a is haploinsufficient. More than $50 \%$ of normal activity is required for normal morphological development of the caudal-most vertebrae (Fig. 7). Interestingly, mutants in Brachyury, a transcriptional regulator that is also expressed in mesodermal precursors in the tail bud, exhibit haploinsufficiency and an allelic series with a similar increased requirement along the rostral to caudal axis (MacMurray and Shin 1988; Stott et al. 1993).

The allelic series of Wnt-3a in mice resembles the series of $w g$ alleles in Drosophila. Nine null alleles of $w g$ are embryonic lethal, two hypomorphic alleles are lethal at the pupal stage (van den Heuvel et al. 1993), and the least severe hypomorphic allele results in viable adults that lack one or both wings (Sharma and Chopra 1976). The range of viability observed in the $w g$ allelic series corresponds to the embryonic lethal, perinatal lethal, and adult viable phenotypes observed in mice with varied amounts of Wnt-3a. The example provided by Wnt$3 a$ suggests that the use of gene targeting to generate hypomorphic alleles of other mammalian Wnt genes could be enlightening.

What is the role of Wnt-3a and what is the significance of the dosage requirements? Two phenotypic features of the $v t$ hypomorph and Wnt- $3 a^{\text {neo }} / v t$ heterozygotes bear a striking resemblance to the phenotype of null mutants. First, all genetic combinations result in axial truncation albeit at different rostral-caudal positions. Thus, the process of axial progession is dependent on Wnt-3a activity from early somite stages until its completion. Earlier work indicates that this reflects a requirement for Wnt-3a for specification or maintenance of mesodermal precursors in the tail bud. Second, somites are absent for a considerable distance rostral to the position at which the axis truncates. Therefore, the axis continues to elongate but somites do not form. Again the position is dependent on the genetic combination and, consequently, the levels of Wnt-3a expression. Thus, Wnt-3a may have a direct role in the development of somitic mesoderm.

The dosage requirements are open to several different interpretations. For example, there may be an absolute requirement for increasing levels of Wnt-3a activity as development proceeds. In one scenario, the levels of Wnt-3a activity are only relevant in so much as they satisfy the demand at a given time for somite formation and tail bud development. Thus, Wnt-3a acts in exactly the same way at all stages; however, the system de- mands increased Wnt-3a activity at later stages than at earlier times. Alternatively, the differing requirement for Wnt-3a activity at different axial levels may relate to the distinct fates of somites forming at these levels. Therefore, whereas, a certain level may be sufficient for a thoracic vertebral fate, higher levels may be necessary to generate caudal vertebrae. Furthermore, it is possible that a constant threshold of Wnt-3a signal is actually required, but a gradual decrease in the transcription of Wnt- $3 a$ occurs in the tail bud. At early stages, Wnt-3a expression may be in considerable excess of that required to achieve the threshold levels of Wnt-3a protein. In this case, if steady-state levels of transcript decrease, two normal alleles of Wnt-3a may only produce a small excess of Wnt-3a. Consequently, loss of activity in either one or both alleles would lead to subthreshold levels of Wnt-3a, causing the arrest of somite formation and axial elongation. Clearly, additional experiments will be required to determine the significance of Wnt-3a dosage requirements. However, these studies underscore the importance of Wnt-3a signaling for mesodermal development in the mouse, and presumably other vertebrates, and provide suggestive evidence that the levels of Wnt signals may be important for different developmental outcomes along the rostral-caudal axis.

In humans, caudal defects including spina bifida, caudal regression syndrome, and sirenomelia bear many characteristics of the Wnt-3a allelic series, including various defects of the lower neural tube, gastrointestinal tract and genitourinary tracts, fusion of the lower limbs, and reduced number of presacral vertebrae (Smith 1982; Buyce 1990; Takada et al. 1994). These devastating birth defects have an incidence of $\sim 1$ in 10,000 and are one of the most common causes of stillbirth and early neonatal death (Pauli 1994). Whereas the etiology of these lower mesodermal defects is not well understood, it is clear that both genetic and environmental factors contribute to the risk (Reece and Hobbins 1986; Werler et al. 1993). It will be of considerable importance to assess the contribution of human WNT gene expression to the genetic risk for these syndromes.

\section{Materials and methods}

\section{Mice}

The following mouse stocks were purchased from the Jackson Laboratory, Bar Harbor, ME: M. musculus castaneus (CASA/ $\left.\mathrm{Rk}, \mathrm{F}_{40}\right)$, C57BL6/J, C57BR/cdJ, 129/SvJ, and vestigial tail (B6C3H-a/A-wa2 vt). A stock carrying the $v t$ mutation, referred to herein as VT, was maintained at The University of Michigan (Ann Arbor) since 1991 by intercrossing without further backcrossing to $\mathrm{B} 6 \mathrm{C} 3 \mathrm{H}$. Mice heterozygous for a null allele of Wnt$3 a\left(W n t-3 a^{n e o} /+\right)$ have been described previously (Takada et al. 1994).

\section{Genetic mapping}

Progeny of the $/ \mathrm{VT}-v t / v t \times M$. castaneus $\mathrm{F}_{1} \times \mathrm{VT}$ - $v t / v t$ backcross were scored at 1-5 weeks of age for the presence or absence of the characteristic $v t / v t$ tail phenotype and the first coat of wavy hair and curly whiskers evident in wa2 homozygotes. Genomic 
DNA was prepared from backcross progeny (liver, kidney, lung, spleen, or tail) by proteinase $\mathrm{K}$ digestion followed by a high salt extraction (Miller et al. 1988). SSLPs were detected by PCR amplification of genomic DNA samples. Primers specific for D11Mit1, D11Mit5, D11Mit22, and Csfgm have been described (Love et al. 1990). Amplification of $M$. castaneus and $v t / v t$ genomic DNA samples produced products of 120 and $160 \mathrm{bp}$ for D11Mit1 primers, 130 and 200 bp for D11Mit5, and 270 and 240 bp for D11Mit22, respectively. The D11Mit1,D11Mit5, and D11Mit22 amplification products were separated by electrophoresis on $2 \%$ agarose $/ 1 \%$ NuSieve gels in $1 \times$ TBE buffer $/ 89 \mathrm{~mm}$ Tris, $89 \mathrm{~mm}$ boric acid, $2 \mathrm{mM}$ EDTA at $\mathrm{pH} 8.0$ ) and visualized by ethidium bromide staining. The Csfgm SSLP was detected by PCR amplification in the presence of $\left[{ }^{32} \mathrm{P}\right] \mathrm{dCTP}$, the products were separated by electrophoresis on $6 \%$ polyacrylamide gels, and visualized by autoradioagraphy.

Osteonectin (Sparc) and Wnt-3a were mapped using RFLPs detected by Southern blot hybridization. The SPARC probe (pC33) was a 1.1-kb fragment of mouse osteonectin genomic DNA [kindly provided by Dr. M. Young, National Institute of Dental Research, Bethesda, MD (Holland et al. 1987)]. The Wnt$3 a$ probe was a mouse cDNA (p9A) isolated from an 8.5 -day embryo mouse library and provided by Dr. Roel Nusse (Stanford University, CA) (Roelink and Nusse 1991; Takada et al. 1994). The probe spans nucleotides 196-1451, including $267 \mathrm{bp}$ of the $3^{\prime}$ UTR and the entire coding region except $67 \mathrm{bp}$ at the $5^{\prime}$ end (Roelink and Nusse 1991). Probes were prepared by radiolabeling purified DNA fragments with $\left[{ }^{32} \mathrm{P}\right] \mathrm{dCTP}$ (NEN) nucleotide by the random hexamer method (Feinberg and Vogelstein 1982). Hybridization of filters containing genomic DNA digested with $B a m H I$ with the SPARC probe detected a CASA/Rk-specific fragment of $3.1 \mathrm{~kb}$ (Buckwalter et al. 1991) and a $V T$-specific fragment of $2.5 \mathrm{~kb}$. The $W n t-3 a$ cDNA probe detected an $8.8-\mathrm{kb}$ $C A S A / R k$ specific fragment and a $5.2-\mathrm{kb} V T$-specific fragment in genomic DNA digested with BgII.

Haplotype analysis and minimization of crossover frequency was used to establish gene order. Genetic distances are reported in centimorgans and the estimated standard error was calculated as the square root of the variance. The variance is equal to $p(1-p) / n$, where $p$ is the recombinant fraction and $n$ is the number of animals tested. When no recombinants were observed between two markers, a $95 \%$ confidence interval was calculated using the formula $P=(1-r)^{n}$, where $P$ is the probability of a particular event $\{0.05$ for a $95 \%$ confidence interval $\}$, $r$ is the maximum distance between the two loci, and $n$ is the number of meioses scored (Friedman et al. 1991).

\section{Detection of Wnt-3a by SSLP}

The Wnt-3a cDNA sequence was analyzed for the presence of simple sequence repeats using a Pustell DNA matrix homology algorithm (MacVector, IBI/Kodak) (Roelink and Nusse 1991). A thymidine-rich region $\left(\mathrm{T}_{4} \mathrm{CT}_{13} \mathrm{CT}_{4} \mathrm{CT}_{3}\right)$ was detected at position 2680-2707 in the $3^{\prime}$-UTR of Wnt-3a. Oligonucleotide primers were designed that flank this region: $5^{\prime} \rightarrow 3^{\prime}$ forward, GACTGACTGTCTTCTGCCTGG; reverse, ACTTTCCCCATTATTTGAAACA. Ten-microliter reactions, containing $10 \mathrm{~mm}$ Tris $(\mathrm{pH} 8.3), 50 \mathrm{mM} \mathrm{KCl}, 5 \mathrm{~mm} \mathrm{MgCl}, 2.5 \mathrm{~mm}$ deoxynucleotides, 0.2 pmole of each primer, and $0.5 \mu \mathrm{l}$ of $\left[\alpha^{-32} \mathrm{P}\right] \mathrm{dCTP}(\mathrm{NEN})$, were overlayed with mineral oil and denatured for $1 \mathrm{~min}$ at $94^{\circ} \mathrm{C}$, amplified for 35 cycles $\left(1 \mathrm{~min}\right.$ at $94^{\circ} \mathrm{C}, 1 \mathrm{~min}$ at $60^{\circ} \mathrm{C}, 1 \mathrm{~min}$ at $\left.72^{\circ} \mathrm{C}\right)$, followed by a final elongation step $\left(10 \mathrm{~min}\right.$ at $\left.72^{\circ} \mathrm{C}\right)$. DNA quantities between 40 and $700 \mathrm{ng}$ were amplified successfully. Reactions were combined $1: 1$ with loading dye, and $5 \mu l(25 \%$ of the PCR reaction) was analyzed by electrophoresis on $6 \%$ acrylamide gels with $8.3 \mathrm{M}$ urea and exposure to X-ray film (Kodak
XAR-5) for $4 \mathrm{hr}$. The fragment amplified from C57BL6/J genomic DNA migrated slower than the amplified products from VT, C57BR/cdJ, and 129/SvJ DNA. The size of this fragment predicted from the BALB/c sequence is 178 bp (Roelink and Nusse 1991).

\section{Sequence analysis of Wnt-3a cDNA}

Total RNA was prepared from adult lungs using a single-step method (Chomczynski and Sacchi 1987), and the sample was enriched for polyadenylated mRNA by chromatography on poly (dT)-cellulose (Sambrook et al. 1989). The Wnt-3a cDNA was amplified in two overlapping fragments by RT-PCR. Primers designed from the published sequence amplified nucleotides 39-639 (forward, GGTCTAGACACTGCAGCCGCGCCACCTCCCAGG; reverse, CCGGATCCCGGCAAACTCCCGAGAGACCATTCC) and nucleotides 540-1211/forward, GGTCTAGATGCAGCAGCCGCCTCCAGGGCTCCC; reverse, CCGGATCCTGCTCCCGTGTTAGGAGCTCTCC) (Roelink and Nusse 1991). The primers included $\mathrm{XbaI}$ and $\mathrm{BamHI}$ recognition sites to simplify cloning the fragments into pGEM-3z (Promega). After digestion with $\mathrm{XbaI}$ and $\mathrm{BamHI}, \mathrm{RT}-\mathrm{PCR}$ products were separated by electrophoresis on $1 \%$ NuSieve agarose, excised, and ligated into pGEM-3z in the presence of the agarose. The ligation mixture was used to transform $\mathrm{DH} 5 \alpha$ cells by electroporation, and colonies were screened on Luria-Bertani medium (LB) plates containing ampicillin (Sigma) and X-gal (BMB). Plasmids were purified by $\mathrm{CsCl}$ gradient centrifugation, and the DNA sequence determined using Sequenase, version 2.0 (U.S. Biochemical) and the following pUC sequencing primers (BMB): forward, $5^{\prime} \rightarrow 3^{\prime}$ GTAAAACGACGGCCAGT; reverse, $5^{\prime} \rightarrow$ 3'CAGGAAACAGCTATGAC.

\section{Whole-mount in situ hybridization}

Female $v t /+$ mice generated by crossing $v t$ homozygotes with C57BL6/J mice, were caged with $v t / v t$ males and observed daily for the presence of copulation plugs (day 0.5 ). At 9.5 and 10.5 $\mathrm{dpc}$ embryos were removed and processed individually for in situ hybridization (Wilkinson 1992). The corresponding yolk sacs were reserved for genotype analysis. Individual embryos were fixed in $4 \%$ paraformaldehyde at $4^{\circ} \mathrm{C}$ overnight, dehydrated in graded methanols, and stored in $100 \%$ methanol at $-20^{\circ} \mathrm{C}$. Genomic DNA was isolated from yolk sacs (Miller et al. 1988 and resuspended in $20 \mu \mathrm{l}$ of sterile water. PCR reactions containing $1 \mu \mathrm{l}$ of DNA were carried out with primers that detect the Wnt-3a SSLP. Embryos with identical Wnt-3a genotype were pooled from two to four litters and analyzed by in situ hybridization with Wnt-3a sense and antisense riboprobes. In addition, litters of entirely one genotype were generated by the following matings: $v t / v t \times v t / v t$ and $v t / v t \times \mathrm{C} 57 \mathrm{BR}$ or $\mathrm{B} 6 \mathrm{C} 3 \mathrm{H} \mathrm{F}_{1}$.

The Wnt-3a antisense riboprobe, spanning nucleotides $222-$ 1451 , was prepared by $S c a$ I digestion of the template p15A (Roelink and Nusse 1991) and transcription with Sp6 polymerase (Promega) using a digoxigenin-labeling kit (BMB). As a negative control, a Wnt- $3 a$ sense probe corresponding to nucleotides 1-1451 was prepared by digestion with $B a m H I$ and incubation with $\mathrm{T}_{7}$ polymerase (Promega). Preparation of the Mox-1 probe (Candia et al. 1992) has been described previously (Takada et al. 1994). Conditions for hybridization have also been described previously (Wilkinson 1992).

\section{Skeleton preparations}

Animals were collected 1-3 days after birth and killed by ether inhalation. Skin and viscera were removed, and the carcass was 
fixed in $95 \%$ ethanol overnight. Samples were placed in alcian blue (Sigma) for 2 days ( $1 \mathrm{ml}$ of $0.3 \%$ alcian blue in $70 \%$ ethanol, $2 \mathrm{ml}$ of acetic acid, $8 \mathrm{ml}$ of $95 \%$ ethanol), dehydrated in $95 \%$ ethanol for 5 days, and counterstained with alizarin red (Sigma) $10.25 \mathrm{ml}$ of $0.1 \%$ alizarin red in $95 \%$ ethanol per $10 \mathrm{ml}$ of $1 \%$ $\mathrm{KOH})$. Specimens were placed in $1 \% \mathrm{KOH}$ for $6 \mathrm{hr}$, and cleared by incubation in $20 \%, 50 \%$, and $80 \%$ glycerol in a stepwise manner. Destaining times for the $50 \%$ and $80 \%$ glycerol steps varied from 1 day to $>2$ weeks, depending on the amount of residual stain. Skeletons were maintained in $100 \%$ glycerol.

\section{Acknowledgments}

We thank all who provided probes: Drs. Roel Nusse (Wnt-3a), M. Young (Sparc), and Chris Wright (Mox-1). We also acknowledge Dr. Robert Lyons and the Reproductive Sciences Molecular Biology Core for development of the Wnt-3a SSLP and purification of plasmid DNA; I. Jill Karolyi for maintaining the Department of Human Genetics Animal Facility, University of Michigan; Natasha Tokarz for technical assistance; and Bill Pavan, Didi Robins, Marion Buckwalter, Sue O'Shea, Dan Burgess, and Amy Lossie for helpful suggestions. This work was supported by grants from the National Institutes of Health to S.A.C. (RO1 HD30428) and A.P.M. and T.L.G. (NRSA HD07652), the University of Michigan Cancer and Genome Centers (S.A.C.), and a postdoctoral fellowship from the Human Frontiers Science Program (S.T.).

The publication costs of this article were defrayed in part by payment of page charges. This article must therefore be hereby marked "advertisement" in accordance with 18 USC section 1734 solely to indicate this fact.

\section{References}

Bedell, M.A., C.I. Brannan, E.P. Evans, N.G. Copeland, N.A. Jenkins, and P.J. Donovan. 1995. DNA rearrangements located over $100 \mathrm{~kb} 5^{\prime}$ of the Steel (SI) coding region in Steelpanda and Steel-contrasted mice deregulate $S 1$ expression and cause female sterility by disrupting ovarian follicle development. Genes \& Dev. 9: 455-470.

Brandon, E.P., R.L. Idzerda, and G.S. McKnight. 1995. Targeting the mouse genome: A compendium of knockouts. Curr. Biol. 5: 625-634.

Buckwalter, M.S., R.W. Katz, and S.A. Camper. 1991. Localization of the panhypopituitary dwarf mutation $(d f)$ on mouse chromosome 11 in an intersubspecific backcross. Genomics 10: $515-526$.

Buyce, M.L. 1990. Birth defects encyclopedia, pp. 297 and 1541. Blackwell Scientific Publications, Cambridge, MA.

Candia, A.F., J. Hu, J. Crosby, P.A. Lalley, D. Noden, J.H. Nadeau, and C.V.E. Wright. 1992. Mox-1 and Mox-2 define a novel homeobox gene subfamily and are differentially expressed during early mesodermal patterning in mouse embryos. Development 116: 1123-1136.

Chomczynski, P. and N. Sacchi. 1987. Single-step method of RNA isolation by acid guanidinium thiocyanate-phenolchloroform extraction. Anal. Biochem. 162: 156-159.

Couso, J.P. and A.M. Arias. 1994. Notch is required for wingless signaling in the epidermis of Drosophila. Cell 79: 259-272.

Fan, C.-M. and M. Tessier-Lavigne. 1994. Patterning of mammalian somites by surface ectoderm and notochord: Evidence for sclerotome induction by a hedgehog homolog. Cell 79: 1175-1186.

Fan, C.-M., J.A. Porter, C. Chiang, P.A. Beachy, and M. TessierLavigne. 1995. Long range sclerotome induction by Sonic hedgehog: Direct role of the amino-terminal cleavage product and modulation of the cyclic AMP signaling pathway. Cell 81: 457-465.

Feinberg, A.P. and B. Vogelstein. 1982. A technique for radiolabeling DNA restriction endonuclease fragments to high specific activity. Anal. Biochem. 132: 6-13.

Friedman, J.M., R.L. Leibel, and N. Bahary. 1991. Molecular mapping of obesity genes. Mamm. Gen. 1: 130-144.

Gruneberg, H. 1957. Genetical studies on the skeleton of the mouse. XIX. Vestigial-tail. I. Genet. 55: 181-194.

- 1963. Disorders of the unsegmented paraxial mesoderm. In The pathology of development: A study of inherited skeletal disorders in animals, pp. 134-139. Blackwell Scientific Publications, Oxford, UK.

- 1974. A re-examination of two skeletal mutants of the mouse, vestigial-tail (vt) and congenital hydrocephalus $(\mathrm{ch})$. I. Embryol. Exp. Morphol. 31: 207-222.

Gruneberg, H. and A. McLaren. 1972. The skeletal phenotype of some mouse chimaeras. Proc. R. Soc. Lond. B. 182: 9-23.

Heston, W.E. 1951. The "vestigial tail" mouse. A new recessive mutation. J. Hered. 42: 71-74.

Holland, P.W., S.J. Harper, J.H. McVey, and B.L. Hogan. 1987. In vivo expression of $\mathrm{mRNA}$ for the $\mathrm{CA}{ }^{++}$-binding protein SPARC (osteonectin) revealed by in situ hybridization. I. Cell Biol. 105: 473-482.

Johnson, R.L., R.D. Riddle, E. Laufer, and C. Tabin, 1994. Ectopic expression of Sonic hedgehog alters dorsal-ventral patterning of somites. Cell 79: 1165-1173.

Lane, T.F. and E.H. Sage. 1994. The biology of SPARC, a protein that modulates cell-matrix interactions. FASEB I. 8: 163173.

Lossie, A.C., M. MacPhee, A.M. Buchberg, and S.A. Camper. 1994. Mouse Chromosome 11. Mamm. Genome 5: S164 S180.

Love, J.M., A.M. Knight, M.A. McAleer, and J.A. Todd. 1990. Towards construction of a high resolution map of the mouse genome using PCR-analyzed microsatellites. Nucleic Acids Res. 18: 4123-4130.

Lyon, M.F. and A.G. Searle. 1989. Genetic variants and strains of the laboratory mouse, 2nd ed. Oxford University Press, New York, NY.

MacMurray, A. and H.-S. Shin. 1988. The antimorphic nature of the $T c$ allele of the mouse $T$ locus. Genetics 120: 545-550.

Mason, I.J., A. Taylor, J.G. Williams, H. Sage, and B.L.M. Hogan. 1986. Evidence from molecular cloning that SPARC, a major product of mouse embryo parietal endoderm, is related to an endothelial cell 'culture shock' glycoprotein of $\mathrm{Mr} 43,000$. EMBO I. 5: 1465-1472.

McMahon, A.P., B.J. Gavin, B. Parr, A. Bradley, and J.A. McMahon. 1992. The Wnt family of cell signalling molecules in postimplantation development of the mouse. Ciba Found. Symp. 165: 199-218.

Michie, D. 1955a. Genetical studies with "vestigial tail" mice. I. The sex difference in crossing over between vestigial tail and rex. I. Genet. 53: 270-279.

- 1955b. Genetical studies with "vestigial tail" mice. II. The position of vestigial in the seventh linkage group. $J$. Genet. 53: 280-284.

Miller, S.A., D.D. Dykes, and H.F. Polesky. 1988. A simple salting out procedure for extracting DNA from human nucleated cells. Nucleic Acids Res. 16: 1215.

Morata, G. and P. Lawrence. 1977. The development of wingless, a homeotic mutation of Drosophila. Dev. Biol. 56: 227240.

Nusse, R. and H.E. Varmus. 1992. Wnt genes. Cell 69: 10731087. 
Greco et al.

Nusse, R., A. Brown, J. Papkoff, P. Scambler, G. Shackleford, A. McMahon, R. Moon, and H. Varmus. 1991. A new nomenclature for int-1 and related genes: The Wnt gene family. Cell 64: 231.

Pauli, R.M. 1994. Lower mesodermal defects: A common cause of fetal and early neonatal death. Am. J. Med. Genet. 50: 154-172.

Purcell, L., J. Gruia-Gray, S. Scanga, and M. Ringuette. 1993. Developmental anomalies of Xenopus embryos following microinjection of SPARC antibodies. J. Exp. Zool. 265: 153164.

Reece, E.A. and J.C. Hobbins. 1986. Diabetic embryopathy: Pathogenesis, prenatal diagnosis, and prevention. Obstet. Gynecol. Surv. 41: 325-335.

Rennebeck, G.M., E.S. Lader, Q. Chen, Z.S. Cai, C. Faust, T. Magnuson, L.R. Pease, and K. Artzt. 1995. Is there a Brachyury the second? Analysis of a transgenic mutation involved in notochord maintenance in mice. Dev. Biol. 172: 206-217.

Roelink, H. and R. Nusse. 1991. Expression of two members of the Wnt family during mouse development-Restricted temporal and spatial patterns in the developing neural tube. Genes \& Dev. 5: 381-388.

Rugh, R. 1990. Organogeng. In The mouse: Its reproduction and development, p. 226. Oxford University Press, Oxford, UK.

Sage, E.H. and P. Bornstein. 1991. Extracellular proteins that modulate cell-matrix interactions. $I$. Biol. Chem. 266: 14831-14834.

Sambrook, J., E.F. Fritsch, and T. Maniatis. 1989. Molecular cloning: A laboratory manual. Cold Spring Harbor Laboratory Press, Cold Spring Harbor, NY.

Schoenwolf, G.C. 1977. The tail (end) bud contribution to the posterior region of the chick embryo. Anat. Rec. 192: 289296.

Searle, A.G. 1961. Tipsy, a new mutant in linkage group VII of the mouse. Genet. Res. 2: 122-126.

Sharma, R.P. and V. L. Chopra. 1976. Effect of the wingless ( $\mathbf{w g}^{1}$ ) mutation on wing and haltere development in Drosophila melanogaster. Dev. Biol. 48: 461-465.

Smith, D.W. 1982. Recognizable patterns of human malformation: Genetic, embryologic, and clinical aspects, 3rd ed. (ed. M. Markowitz) vol VII, p. 486. W.B. Saunders Co., Philadelphia, PA.

Stark, G.D. 1977. Referral and assessment. In Spina bifida: Problems and management, pp. 73-79. Blackwell Scientific Publications, Oxford, UK.

Stott, D., A. Kispert, and B.G. Herrmann. 1993. Rescue of the tail defect of Brachyury mice. Genes \& Dev. 7: 197-203.

Takada, S., K.L. Stark, M.J. Shea, G. Vassileva, J.A. McMahon, and A.P. McMahon. 1994. Wnt-3a regulates somites and tailbud formation in the mouse embryo. Genes \& Dev. 8: 174 189.

Tam, P.P.L. 1984. The histogenetic capacity of tissues in the caudal end of the embryonic axis of the mouse. J. Embryol. Exp. Morphol. 82: 253-266.

. 1986. A study on the pattern of prospective somites in the presomitic mesoderm of mouse embryos. J. Embryol. Exp. Morphol. 92: 269-285.

. 1989. Regionalisation of the mouse embryonic ectoderm: allocation of prospective ectodermal tissue during gastrulation. Development 99: 109-126.

Tam, P.P.L. and R.S.P. Beddington. 1987. The formation of mesodermal tissues in the mouse embryo during gastrulation and early organogenesis. Development 99: 109-126.

Tam, P.P.L. and S.-S. Tan. 1992. The somitogenic potential of cells in the primitive streak and tail bud of organogenesis stage mouse embryo. Development 115: 703-715.

van den Heuvel, M., C. Harryman-Samos, J. Klingensmith, N. Perrimon, and R. Nusse. 1993. Mutations in the segment polarity genes wingless and porcupine impair secretion of the wingless protein. EMBO I. 12: 5293-5302.

Werler, M.M., S. Shapiro, and A.A. Mitchell. 1993. Periconceptional folic acid exposure and risk of occurrent neural tube defects. J. Am. Med. Assoc. 269: 1257-1261.

Wilkinson, D.G. 1992. Whole mount in situ hybridization of vertebrate embryo. In In situ hybridization: $A$ practical approach, pp. 75-83. Oxford University Press, Oxford, UK. 


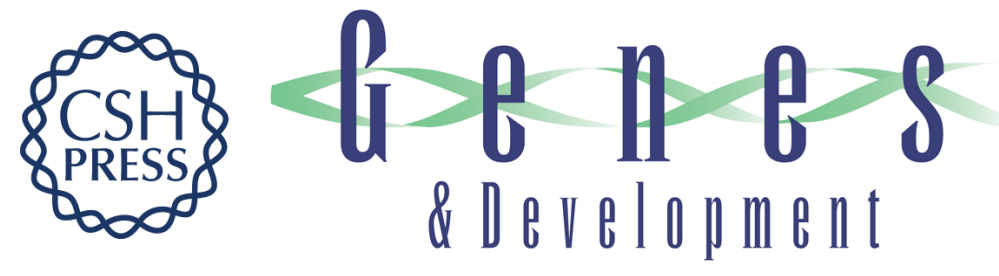

\section{Analysis of the vestigial tail mutation demonstrates that Wnt-3a gene dosage regulates mouse axial development.}

T L Greco, S Takada, M M Newhouse, et al.

Genes Dev. 1996, 10:

Access the most recent version at doi:10.1101/gad.10.3.313

References This article cites 46 articles, 10 of which can be accessed free at: http://genesdev.cshlp.org/content/10/3/313.full.html\#ref-list-1

License

Email Alerting

Service

Receive free email alerts when new articles cite this article - sign up in the box at the top right corner of the article or click here.

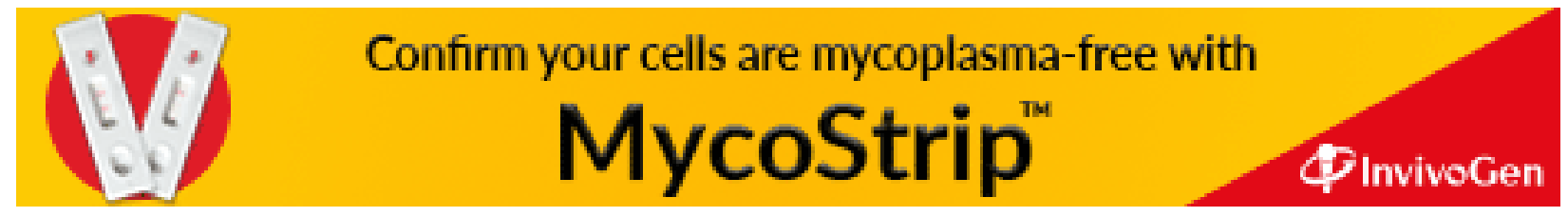

